\title{
Wanting to Achieve Something Together With Others-A Narrative Study
}

\author{
Ingrid Lindahl \\ University of Kristianstad, Kristianstad, Sweden
}

\begin{abstract}
This study is about two educators (tutors) who are responsible for management and development in a preschool and their accounts in connection with the project "Metamorphosis: Children, Educators, Companies, and Local Municipality in Collaboration for a Sustainable Development". The project is based on a philosophy concerning children, citizenship, and the preschool as a place of sharing values and doing democracy, which posits that cooperation within a local municipality could be a way to contribute towards sustainable development. Surplus materials from companies are being put to use, and work done in co-operative efforts among participants of varying ages is seen as a part of "lifelong learning". The objective of this study is to highlight the meaning and importance of "conveying of identity" the educators place on themselves in their work as tutors in doing democracy. Ultimately, the study is expected to contribute to the knowledge of the tutorial work of educators in connection with this project. It is a narrative study, taking a social constructional perspective, based on the principle that meaning and significance are created through linguistic communication in a certain cultural and historical context. The empirical material consists of the two educators' own "reflecting diaries" and interviews focusing on the significance the pedagogues put on themselves in this context. Data collection was carried out over the course of one year. The preliminary result of the study is a meta-story titled "Wanting to Achieve Something Together With Others", which relates Sara's accounts, and "Cooperation and I" based on Annika's story. The educators' shared philosophy concerning children, citizenship, and doing democracy seems to play an important part in their reflections and in the significance they attribute to themselves.
\end{abstract}

Keywords: citizenship, lifelong learning, tutor, doing democracy

\section{Introduction}

This article presents conversations between two educators (tutors) around their experiences with a project promoting cooperation among children, educators, and business for sustainable development in a small municipality in the south of Sweden. The project also aims to contribute to the development of democratic values and methodologies in preschools and primary schools which includes the commitment from "Sesam" and local businesses. "Sesam" is an ongoing project that includes the municipal department of "individual and family care", the employment office, and the regional social insurance office which, together with the upper secondary school, work to help unemployed adolescents and adults obtain employment or further education. Sesam is responsible for collecting and overseeing the storage and distribution of surplus materials left over from the production of local business, in accordance with an agreement with the local council.

Ingrid Lindahl, Ph.D., senior lecturer, School of Education and Environment, Kristianstad University. 
For sometime, preschools have been working on the theme of "light", and therefore many children will choose "light" as their starting point when they begin to create using the materials from the project "Metamorphosis: Children, Educators, Companies, and Local Municipality in Collaboration for a Sustainable Development" (hereinafter referred to as Metamorphosis Project). Here, a natural science (light) project in preschool becomes a social project concerning the world. The children are participating in a wider social context by engaging in creative activities rather than exploring the different functions and components of light. The children's imaginations are given free rein, which could also be considered a right of children, that is, the children's right to freedom of speech, according to the Convention of Children's Rights.

The knowledge and experiences that result will be spread through various forms of documentation, a responsibility held mainly by the "tutors" (standby teachers for support and development in pedagogical work, educated at the Reggio Emilia Institute of Stockholm). In connection to the Metamorphosis Project, these tutors have been instructing other pedagogues in pedagogical documentation, a prerequisite for pedagogues to be able to follow children's as well as their own learning processes. The focus of this study is on the experiences of the tutors concerning the Metamorphosis Project and their capacities as instructors in pedagogical documentation associated with the project.

\section{A Philosophy of Values and Citizenship}

Preschool can be considered a place where, first and foremost, values are transmitted, discussed, and constructed (Rinaldi, 2006). The term "education" is therefore closely related to the concept of values, where "to educate" also means - and in certain respects primarily means - "to educate each individual in each culture, in order to make these values intrinsic, visible, conscious, and shareable" (Rinaldi, 2006, p. 38). Values that are designated as basic in the work of Reggio Emilia are: (a) the value of subjectivity, which is viewed in terms of wholeness and integrity; (b) the value of participation or participation as a value; and (c) the value of democracy, which is embedded in the concept of participation (Rinaldi, 2006, p. 39).

Arendt (1958/1977) argued that subjectivity is not a psychological condition, but a social and political one. Thus, she put subjectivity in the actual act. She argued that peole are created through their actions in a certain context, that is, together with others. In this perspective, democracy is learned through actions, which is expressed in the title of this article. Nevertheless, the actions are only possible where there is plurality, that is, where other people can act simultaneously. Herein lie the ethical and democratic aspects.

Dialogues are of central and absolute importance, not only in the exchange but as a process of transformation in which one loses all possibility of absolutely controlling the final result. Other ways to look at dialogues, a dialogue built on contestation and opening the Other without any fixed goal to reach. "And it goes to infinity, it goes to the universe, you can get lost" (Rinaldi, 2006, p. 184). In the end, a child is understood as a competent citizen, an expert on his/her own life, having opinions that are worth listening to. This also implies that children have the right and competence to participate in collective decision-making.

The Reggio Emilia approach emphasizes ethical and democratic values and the view of preschool as a meeting place where different perspectives are exchanged. Preschool is considered a place where democracy, through these exchanges, is "made" (Dahlberg \& Moss, 1995). The Metamorphosis Project builds on the philosophy of children and society, which could be reflected in this philosophy. It is a philosophy expressing a pedagogical idea about the world, challenging people's thinking about themselves and the world around them. 
Thus, it is a philosophy that emphasizes the importance of dialogue for change and creativity, striving to combine democracy with fantasy and science.

\section{Aim and Methods}

\section{Research Objective}

The objective of this study is to highlight the meaning and importance educators put on themselves (conveying of identity) in their work as tutors in doing democracy. Ultimately, the study is expected to contribute to the knowledge of the tutorial work of educators in connection with this project.

\section{A Narrative Study-A Social Constructive Perspective}

The study is based on a social constructive perspective, which implies that life stories are seen as socially situated acts that convey identity (Mischler, 1999; Berger \& Luckman, 1966/1979; Burr, 1995). In the concept of "conveying of identity" lies an understanding of identities as something to do, rather than an expression of who we are (Arendt, 1958/1977). Bloom (1996) showed that through self-reflection upon events in historical succession, people "make" their identities. From a social constructive perspective, ideas of the existence of a true, real "reality" are challenged. The stories, therefore, are not seen as expressions of a "factual" event, how it was or is. They do not express any underlying "essence" but rather intention and a certain cultural and historical context (Burr, 1995). A characteristic of the narrative analysis is its reflective nature, which implies that the relationship between the knowledge one produces (what) and the way one "does" knowledge (how) is heeded, that is, one interprets one's own construction of knowledge and one's own interpretations. It is a matter of thinking about one's own thinking, a kind of meta-thinking (Alvesson \& Sköldberg, 1994).

Significant aspects of this perspective are the frames of cultural interpretation, shared by people and called by Mischler (1999) "culturally shared stock knowledge" (p. 10). They pave the way for dialogue and communication, although it may not be done consciously. Rather, as Burr (1995) put it, "When people use repertoires, they are not necessarily acting in a Machiavellian fashion but just simply doing "what seems appropriate' and 'what comes naturally' in the situation" (p. 122).

Life stories, considered as socially situated actions and as conveyors of identity, suggest that the narrative is considered as a social life, not just verbal or written representations of the same. This deals with how the contents of the life stories are attributed with certain intentions and significance through telling stories (Mischler, 1999). The identities of the tutors are thus created through their telling and their stories. Mischler (1999) stressed the importance of considering life stories as co-produced in that they grow in the dialogue that takes place between the interviewer and the interviewee. The statement "No one writes his/her own story" leads automatically to the question "Whose voice is heard?". In view of this, special demands are placed on the researchers' critical self-reflective abilities in the narrative analysis.

Riessman (1993) described a five-step model of narrative analysis. In this study, the steps can be described briefly as follows: (a) visiting the preschool and observing the activities during one morning, wanting to familiarize with the children and the activities. The reflective protocols of the participating tutors were presented; (b) holding conversations with the pedagogues; (c) transcribing the conversations; (d) after reading the text through, formulating questions and discussing them with the pedagogues to enhance the author's appreciation of the text; and (e) creating a meta-story from the transcribed conversations and the reflective protocols. The method of analysis involves the creation of a text, where the author tries to visualize and 
problematize the identity conveyances and how it emerges during the course of the project. In light of the perspective presented here, the identity conveys between interviewer and interviewee.

The meta-stories are tied to the central contents-what is in the conversations-presented here as "Wanting to Achieve Something Together With Others" (referring to Sara) and "Cooperation and I" (referring to Annika). The final text should show different possible interpretations and "invite" the reader to make his/her own interpretation. The conversation between the reader and the text is thereby expected to continue.

\section{Sara-Wanting to Achieve Something Together With Others}

Prominent in Sara's story is her wish to help others, pedagogues, as well as children, in their explorations. All of her reflections emanate from and end in questions. What the author looks for in her questions is Sara's own identity process in this, leading her to the same line of questioning and, further, to new questions of reflection. Here, the author follows Sara through her thoughts, letting her largely speak for herself. A prevalent question is, "If I do her story justice, whose voice is heard?". Of course, the intention with this meta-story is to arrive at a fair interpretation of Sara's identity as it is conveyed (and transformed) in the course of the narrative.

At the start of the project, Sara formulates a question, posing it to herself as well as to the participating pedagogues: "What do we listen for in our documentation?". Her use of the word "we" is prominent in the texts in the reflecting diary, starting with the early entries.

The work of observation is now directed towards the children and determining what they are doing, trying to learn their theories on things, and challenging them in their actions. But, also, a practical, organizational side of tutoring emerges. The question is how to make it possible for all to participate in the work of reflection. The initial experience leads to minor changes of organization. However, it is mainly what goes on in the reflective conversations that reveals what is at the forefront of Sara's mind. She says:

How can we create opportunities and meeting places for children in preschool and primary school in order to make the children visible in a positive way, break patterns and preconceived conceptions, be blank slates, curious pedagogues looking for the competence of the children?

Framework issues are limiting and liberating material, environment, attitude, and ways of work are significant for the place of children in the surroundings. We should not evaluate the routes the children take, but be fascinated, curious, and try to understand them. We should understand the importance of this and transfer it into everyday life.

Here, Sara's view of children could be related to the project philosophy, that is, the Reggio Emilia philosophy concerning children and values. Children must be made visible in their own right, without the valuation or preconceptions of adults. The task of the pedagogues is to create opportunities for the children to explore their own reality.

Sara and Annika came across something in the Metamorphosis material that they saw as presenting opportunities. How to make the participating pedagogues come to the same conclusions and see the possibilities? One interpretation of Sara's text above could be that she, with her words, is actively seeking to influence the pedagogues to adopt a certain way of thinking. The last sentence, "(to) understand the importance of this and transfer it into everyday life", seems to be directed towards the participating pedagogues. One question at this point is how Sara considers her own tutorial role in this context.

Sara likes to talk about her own learning, always joined to others and other people's experiences, all in line with a social constructive point of view in searching for knowledge and with the philosophy of the project. Learning the meaning of pedagogical documentation and the methods within it demands a lot of training. Sara 
returns to this throughout the project. In the author's interpretation, it takes time to acquire a project philosophy containing "pedagogical documentation". But, so far, the pedagogues are not considered as "they"; they are still incorporated in the "we".

At the initial tutorial occasion, Sara and Annika work with the children while the pedagogues take a more passive attitude by merely observing. The observers document the experience through writing and photography. The roles shift, enabling all to try both methods. On the second occasion, Sara and Annika compile the material by connecting images and text and observing the strategies of each child. This is followed by joint reflection and, as Sara put it, "the discovery of a connection to everyday preschool life".

\section{"We" Seek the Core of the Documentation: What Is the Significance?}

Often, Sara returns to this expression. The question is: What does "we" mean here? Is it "we", or could it be an expression of her ambition regarding the pedagogical documentation within the project? About halfway into the project, the reflection assumes a different note. Now, "we" transforms into something more like "they". One interpretation is that the two tutors now realize that leading a project is more than an exciting venture in which all participants are co-constructors of knowledge and culture. Not everybody participates in getting insights, and Sara also encounters obstacles and resistance. She says, "Now, the stress has changed from 'we want' to 'we want to give"'.

Maybe a social constructive perspective that includes everybody as co-constructors of culture and knowledge is hard to put into social/pedagogical practice if at the same time there is an assignment to "develop" and "change". The last sentence, "We want to catch a sight of the perspective of the child in this work", expresses exactly what has been a central point of departure in the project of documentation. Still, this point of departure emerges throughout the duration of the project. One explanation for this is that the project is about processes of change and that the attitudes of the participating pedagogues are never made clear. They like to participate, but the intellectual part - the desire to reflect and learn new things, to be prepared to change ingrained opinions and methods - could prove to be a difficult process for many. When Sara states "We want to give", she means "they need", but such a way of expression would be counter to the project philosophy, which considers human relations to be meetings between equal subjects. From a social constructive perspective, the world is given significance and meaning through the way of communicating, the language, and ways of expression.

The common creation of meaning is expected to happen on a more equal basis, where the theories of all on different phenomena could be of value and an object of common exploration. Through emphasizing multiplicity, whereby reality can be understood in many ways, it is possible to go beyond what is taken for granted. In this lies emancipatory possibilities and a forward-looking perspective (Dahlberg \& Moss, 1995). But "we" viewed in this way could only be "we" when embracing the project philosophy. Maybe the pedagogical possibilities of multiplicity are feasible only if there is an agreement about this.

\section{To Reflect on the Smallest Details}

Sara tells about a group of three-year-olds whose task was to build a house for dinosaurs.

Sara emphatically expresses that nothing concerning the acts of the children is too small or insignificant to reflect on. She connects this to her own learning in terms of "we". Nevertheless, the last sentence is perceived to be written with an "ulterior motive". To really emphasize the process is something of a struggle in contemporary pedagogical discourse, which reflects the emphasis on performance and measurement of 
performance that has penetrated today's preschools. According to the project philosophy, the focus is not placed on the results of creation and exploration; the so-called result is never really perceived as a result, but rather as an image of a "now", a process that encompasses all that preceded it. Children have a right to be proud of this image and to be allowed to communicate it to adults and other children.

\section{Criticism and Ethics}

In Sara's writing and in the conversations, there also emerges a critical stance towards the acts of her selves. Sara says:

What I could criticize is the fact that we are creating an artificial situation for children and pedagogues. Is it ethical when the pedagogues back off and observe the children in such a situation? Are we objectifying the children? Do we describe the children as they would like to be described?

\section{"My" Project Philosophy Will Turn Into "Yours"}

The conversations drift into Sara's view of how the project will develop. The conveying of identity of a tutor also presumes emphasizing theories of understanding. Thus, learning cannot be reduced merely to "doing" and "talking about" these doings. Something has to be added that challenges thinking about the "doing" and brings new insight, as emerges in Sara's stories at the end of the project.

\section{Annika- "Cooperation and I"}

The stories of Annika and Sara are very similar. They cooperated in the course of the project, and their reflections are founded on their common documentation during the work. What can be said of Annika's conveying of identity that emerges during this process? The meta-story based on Annika's stories is called "Cooperation and I".

\section{Cooperation for Democracy}

One overriding purpose for the Metamorphosis Project is to develop cooperation between preschools and primary schools with "Sesam" and local businesses to make a contribution towards sustainable development. The motive of democracy and the question of "lifelong learning" are frequently recurring themes in Annika's stories. Also, she is committed to the overall responsibility of the project.

This continuous flow is a prerequisite for the overall durability of the project. Without continuity, the risk of the project becoming transient is apparent, without possibilities to be motivated by "a sustainable development, democracy, and lifelong learning", which constitutes the basis of the project.

\section{To Be Allowed to Blossom in Another Language}

According to Annika, what is made visible by the pedagogical documentation is what is happening in the meeting between the children. She says:

Cooperation, both between individuals and within the group as a whole occurred in a social and meaningful context, interacting both ways. The non-verbal children had an opportunity to blossom in another "language". This, I think, supports the idea of "lifelong learning", where the learning is submitted to the aims and decisions of the children.

Annika refrains from problematizing the learning process of the participating pedagogues, as Sara is seen do. It is the tutors who encourage the children; what happens to the participating pedagogues is not the first thing to be reflected upon. What is happening to the children seems always to be positive and totally in line with the project philosophy. 


\section{Who Am "I" in This Cooperation?}

In the conversations with Annika, the author grapples with the question of how she looks at herself in this context. Like Sara, Annika often chooses to speak in terms of "we". One question to return to during the conversations is how Annika views her own role as a tutor in this project. Annika likes to point to an important lesson learned from this project:

Our reciprocal learning and our dependence on the surroundings are well in line with the values of Reggio Emilia and the Metamorphosis Project. Joy, happiness, fantasy, facts, thoughts, creativity, the concrete and the abstract in a meaningful context are all expressions of the possibilities of the hundred languages.

\section{Conclusion}

What could be said of the conveying of identity of the tutors? They are brought up in the so-called Reggio Emilia philosophy (here: the project philosophy), which manifests itself in their choice of words and way of thinking. One might say that "A philosophy on children, citizenship, and the preschool as a place of sharing values and doing democracy constitutes a fundamental aspect in their conveying of identity as pedagogistas". The project philosophy is hard to penetrate, and likewise, it is difficult to reach the subjective meaning of the stories. Certainly, you do not look for an underlying "essence" in a constructional perspective, as one does not exist. Instead, intention and significance are created through spoken or written communication in a social interplay (Burr, 1995). Nevertheless, the author's contribution to this co-constructive process could be debated. The fact that the author, as a researcher, associates herself with the project philosophy should be put under scrutiny. This could be interpreted as if the interviews would be perceived as merely "rhetoric" rather than an expression of the significance Sara and Annika like to convey in their reflecting diaries and what is created in the conversation. In both reflective diaries, the reflections look forward as well as backward. The children lead the way-their acts could never be "wrong", but reveal things, leading to what is ready to be developed. This readiness to "be developed" represents a responsibility for Annika and Sara. When talking about themselves, they do so in terms of "we"- "We need to improve", and so on. Finally, for Annika and Sara, the project philosophy seems to play a decisive part in their reflections and in the significance they attribute to themselves as tutors in this project.

\section{References}

Alvesson, M., \& Sköldberg, K. (1994). Tolkning och reflection-Vetenskapsfilosofi och kvalitativ metod (Interpretation and reflection—Philosophy of science and qualitative methods). Lund: Studentlitteratur. (In Swedish)

Arendt, H. (1958/1977). The human condition. Chicago, I.L.: University of Chicago Press.

Berger, P., \& Luckman, T. (1966/1979). The social construction of reality a treatise in the sociology of knowledge. Harmondsworth, Middlesex: Penguine Books.

Bloom, L. (1996). Stories of one's own: Non-unitary subjectivity in narrative representation. Quality Inquiry, 2(2), 198-221.

Burr, V. (1995). An introduction to social constructionism. London, U.K.: Routledge.

Dahlberg, G., \& Moss, P. (1995). Ethics and politics in early childhood education. London, U.K.: Routledge Falmer.

Mischler, E. G. (1999). Storylines: Craftartists' narratives of identity. London, U.K.: Harward University Press.

Riessman, C. K. (1993). Narrative analysis. Newbury Park, C.A.: Sage.

Rinaldi, C. (2006). In dialog with Reggio Emilia: Listening, researching and learning. London and New York: Routledge. 